\title{
Childhood obesity in the Middle East: a review
}

\author{
P. Mirmiran, ${ }^{1}$ R. Sherafat-Kazemzadeh, ${ }^{1}$ S. Jalali-Farahani' and F. Azizi ${ }^{7}$
}

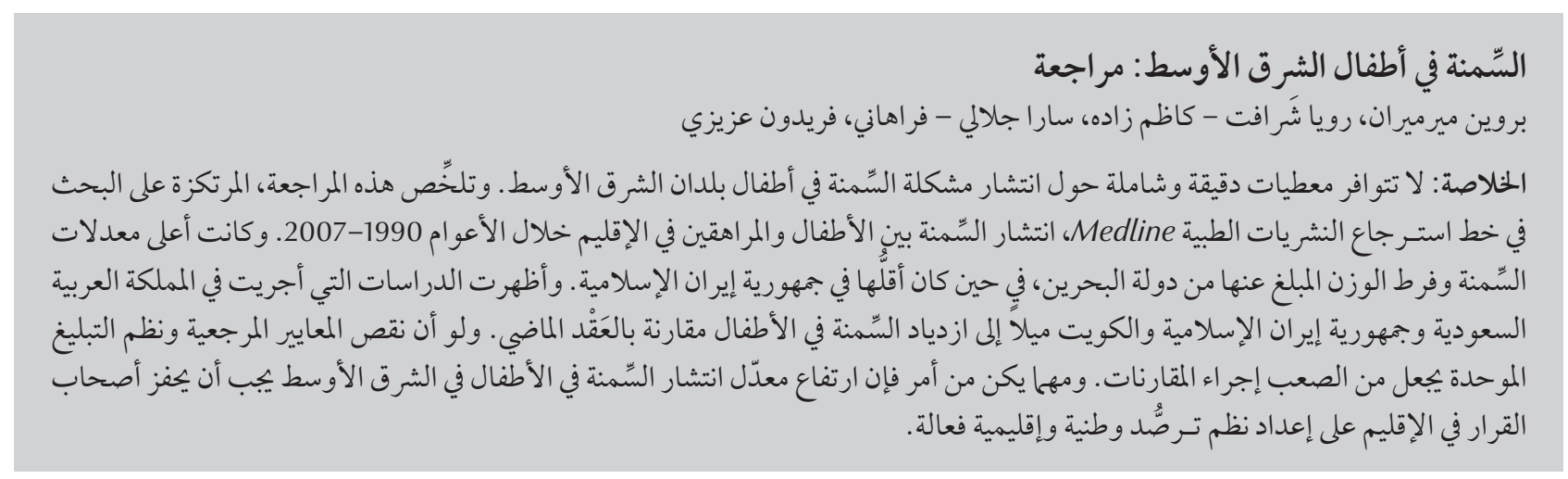

ABSTRACT Accurate and comprehensive data on the extent of the problem of childhood obesity is lacking in countries of the Middle East. This review, based on a Medline search, summarizes the prevalence of obesity among children and adolescents in the region during 1990-2007. The highest rates of obesity and overweight were reported from Bahrain and the lowest from the Islamic Republic of Iran. Studies from Saudi Arabia, Islamic Republic of Iran and Kuwait showed an upwards trend in childhood obesity compared with a decade ago. Lack of uniformity in reference standards and reporting systems renders comparisons difficult. Nevertheless, the high prevalence of childhood obesity in the Middle East should stimulate policy-makers in the region to set up effective national and regional surveillance systems.

\section{Revue sur l'obésité de l'enfant au Moyen-Orient}

RÉSUMÉ Les pays du Moyen-Orient manquent de données précises et exhaustives sur l'étendue du problème de l'obésité de l'enfant. Cette revue, qui repose sur des recherches effectuées dans Medline, offre une synthèse sur la prévalence de l'obésité chez les enfants et les adolescents dans cette région, entre 1990 et 2007. Les taux d'obésité et de surpoids les plus élevés ont été enregistrés à Bahreïn, et les plus faibles en République islamique d'Iran. Des études réalisées en Arabie saoudite, en République islamique d'Iran et au Koweït ont montré une tendance à la hausse de l'obésité infantile par rapport à la décennie précédente. Le manque d'uniformité dans les normes de référence et les systèmes de signalement rend les comparaisons difficiles. Néanmoins, la forte prévalence de l'obésité de l'enfant au Moyen-Orient doit inciter les responsables politiques de la région à mettre en place des systèmes de surveillance nationaux et régionaux efficaces. 


\section{Introduction}

Obesity has long been considered as a predisposing factor that affects an individual's health. Yet, the importance of obesity and overweight among children has only been highlighted relatively recently $[1-3]$. Worldwide, there are a total of 155 million ( 1 in 10) children overweight, and around 30-45 million classified as obese [4-6].

Investigators now suggest that indices of adiposity are useful screening tools for multiple risk factors such as hyperlipidaemia, insulin resistance and high blood pressure among children [1]. The incidence of obesity-related conditions is increasing steeply among adolescents; these include type 2 diabetes, a disease that was previously not normally seen until middle or older age [5]. Childhood body mass index (BMI) has been shown to be associated with adult adiposity [1] and its related conditions [7]. The World Health Organization (WHO) is working with its Member States to implement the Global Strategy on Diet, Physical Activity and Health to combat childhood obesity [8]. WHO estimates that threequarters of all deaths in the developing world by the year 2020 will be due to noncommunicable diseases [9].

In developed societies, several studies have shown increasing numbers of overweight children [1,10-12]. Although many nutritional surveys were conducted in the 1980s and 1990s in developing countries, they were not generally analysed for the prevalence of overweight, focusing mainly on the underweight and malnutrition [13]. There are no consistent data on overweight available for more than $70 \%$ of children aged less than 5 years [13]. Nonetheless, reports indicate that worldwide more than 22 million children under 5 years old are obese or overweight, and more than 17 million of them are presumed to live in developing countries $[9,12]$. A study of 94 developing countries showed that the nations with the highest prevalence of overweight were located mainly in the Middle East, North Africa and Latin America [13].

The Middle East region has the highest dietary energy surplus among developing countries, and there is evidence of a rapid rise in noncommunicable disease risk factors, especially obesity [12]. If there is to be a regional commitment to control the growing problem of childhood obesity, access to reliable national data and accurate information about the rates and time trends are indispensable. Still, there are few studies that have reviewed the extent of this problem in this region, and those that have did not take account of the methodology or tabulate the data comprehensively. In this review we explore studies about the extent of overweight and obesity among children and adolescents in countries of the Middle East indexed in Medline, the most widely used medical database. We endeavour to provide a comprehensible systematic review of the studies in the region with the emphasis on cut-off values and definitions of overweight and obesity.

\section{Literature review methods}

We retrieved surveys concerning children's anthropometric data from different countries. Due to the limited availability of national surveys, articles with local datasets (e.g. limited to 1 province) were also included to determine a raw estimate of the extent of childhood obesity in the region.

\section{Definition of terms}

There are multiple reference values currently used as the standards to assess children's obesity:

- The WHO reference defines BMI percentiles as cut-offs for overweight among 10-19-year-olds and weightfor-height Z-scores for obesity in children $<10$ years old. The reference values include age- and sex-specific data from the first National Health and Nutrition Examination Survey (NHANES I) collected in 197174 in the United States of America [14-16].

- The Centers for Disease Control and Prevention (CDC) reference uses BMI percentiles for ages $2-20$ years. The year 2000 reference included BMI-for-age-growth charts and was a revised version of the 1977 National Health Care Survey (NCHS) growth charts $[14,17]$.

- The Childhood Obesity Working Group of the International Obesity Task Force (IOTF) reference uses sex-and age-specific BMI cutoffs that correspond to BMI $25 \mathrm{~kg} / \mathrm{m}^{2}$ for overweight and $30 \mathrm{~kg} / \mathrm{m}^{2}$ for obesity at age 18 years $[14,18]$. The reference population was made up of 6 nationally representative datasets.

- The NCHS reference data use subscapular and triceps skinfold thickness $[19,20]$.

For this review we included all suitable reports despite differences between them in the definitions of childhood obesity.

\section{Method of selection}

An extensive literature review was performed using the Medline search engine. We first retrieved all medical subject headings $(\mathrm{MeSH})$ related to the concepts of nutrition, obesity, overweight, body weight, BMI, statistics, epidemiology, children and adolescents, as well as keywords for categorizing articles according to countries of the Middle East. Finally, we developed a set of major topic headings for these concepts: "Obesity/epidemiology", "Children", "Growth and development" and "Middle East". We employed these MeSH words, limiting the search to the time period 1990-2007.

Performing the search in PubMed, we obtained 70 results. These included studies pertaining to the prevalence of obesity among migrants from Middle East origin in other countries; the 
prevalence of related conditions such as diabetes or cardiovascular diseases and their genetic and environmental risk factors; body perceptions; social and physical habits in a country; and the nutritional status of wasting and malnourished children, but not obese ones. We excluded these studies. The results included countries such as Turkey that is included in $\mathrm{MeSH}$ as a Middle East country but is not in the Eastern Mediterranean Region (EMR) of WHO, plus there were African countries such as Somalia and Sudan that are part of EMR but not listed by MeSH as a Middle Eastern country. We excluded these countries for convenience of searching and drawing conclusions.

\section{Surveys}

The final review covered 48 articles retrieved from Medline-indexed journals that were directly related to the prevalence of overweight and obesity among children and adolescents in countries of the Middle East.

The studies focused mainly on the prevalence of childhood obesity either in a local or national setting. Multistage, random sampling methods were used in all the papers, and all were cross-sectional except for 2 studies, from Saudi Arabia and Oman, which were cohort studies. Because of the limited availability of nationally representative anthropometric data and the lack of uniformity in the sampled populations in the available reports, we selected only reports with larger sample sizes or greater coverage of different age groups. In this review we have summarized and tabulated the methodology and prevalence rates in each paper for comparison. Finally, we compared the reviewed studies with reports from both other developing and developed countries.

\section{Regional coverage of studies}

The largest number of studies on the epidemiology of obesity among children and adolescents were from Saudi Arabia and the Islamic Republic of Iran (11 each), followed by Kuwait (7 articles) and Bahrain (4 articles). Other countries included were: Jordan, Lebanon, Libyan Arab Jamahiriya, Oman, Pakistan, Qatar and United Arab Emirates. We were not able to retrieve any articles originating from Afghanistan, Iraq or Syrian Arab Republic during this period (Table 1).

Of the 48 selected articles 13 involved data from a sample size greater than 5000 individuals (Table 1); the largest sample sizes were from the

\begin{tabular}{|c|c|c|c|}
\hline Country & $\begin{array}{l}\text { No. of articles } \\
\text { retrieved }\end{array}$ & $\begin{array}{l}\text { Assessments } \\
\text { in }>1 \text { province }\end{array}$ & $\begin{array}{c}\text { Studies with > } \\
5000 \text { cases }\end{array}$ \\
\hline Bahrain & 4 & + & 0 \\
\hline Islamic Republic of Iran & 11 & + & 2 \\
\hline Jordan & 1 & + & 1 \\
\hline Kuwait & 7 & + & 3 \\
\hline Lebanon & 4 & + & 1 \\
\hline Libyan Arab Jamahiriya & 1 & + & 0 \\
\hline Oman & 1 & - & 0 \\
\hline Pakistan & 2 & - & 0 \\
\hline Qatar & 2 & + & 1 \\
\hline Saudi Arabia & 11 & + & 4 \\
\hline United Arab Emirates & 4 & + & 1 \\
\hline
\end{tabular}

Islamic Republic of Iran (21111), United Arab Emirates (16391), Kuwait (14 659) and Saudi Arabia (12 701). Studies from Saudi Arabia and Oman presented cohort studies for the trend of obesity in different ages; others were cross-sectional studies using multistage stratified random sampling for data collection.

The studies covered different age groups and in order to compare datasets in a general way we tabulated the information covering the widest age range and the greatest sample size in each country in Table 2. Bahrain, Jordan, Libyan Arab Jamahiriya, Oman and Qatar did not have reports from every age group, while there were single reports from the United Arab Emirates, Saudi Arabia and Lebanon covering large samples from all groups. As illustrated in Table 3, different surveys employed different standards for defining the cutoff point for overweight/obesity. After analysing the studies shown on Table 2 , we then summarized the prevalence rates from surveys covering the largest sample size in each country in Table 3. Different rates in both sexes were shown if the data were available in the article.

\section{Prevalence of obesity and overweight in the Middle East}

The highest prevalence of overweight was reported from Bahrain (38.5\%) [41], followed by Kuwait, with a rate of $31.8 \%$ among girls [27]. The lowest prevalence of obesity was reported from the Islamic Republic of Iran (2\%-3\% by different cut-offs) [22], followed by Lebanon (3.2\% among 3-19 year-old girls) [31]. The study from Bahrain included only 584 girls and since there were larger reports from this country, we did not show these results in the tables.

Among the Middle East countries our review demonstrates that there are few nationally representative studies on 
the pattern of obesity among children that can be used for future reference. A year 2000 review of the available national datasets showed that the rates of overweight exceeded 5\% in Kuwait and Qatar, suggesting that a population-wide shift in which overweight was replacing wasting, but they also reported rates lower than 5\% in Afghanistan, Bahrain, Islamic Republic of Iran, Oman, Pakistan and Yemen, indicating that underweight was still a major problem [13]. Our review supports the notion of nutrition transition in this region; the highest levels of overweight and obesity were among adolescents in Bahrain and Kuwait (over 30\%). By comparison, obesity was reported to be $29 \%$ among Canadian, 26\% among Italian and $19.7 \%$ among Dutch adolescents [20].

\begin{tabular}{|c|c|c|c|c|c|c|c|}
\hline \multirow[t]{2}{*}{ Country } & \multirow[t]{2}{*}{ Ref. no. } & \multirow{2}{*}{$\begin{array}{c}\text { Year of } \\
\text { publication }\end{array}$} & \multirow[t]{2}{*}{ Sample size } & \multirow[t]{2}{*}{ Region } & \multicolumn{3}{|c|}{ Age group $^{a}$} \\
\hline & & & & & Preschool & Childhood & Adolescence \\
\hline Bahrain & [21] & 2003 & 506 & $\begin{array}{l}\text { Different } \\
\text { provinces }\end{array}$ & - & + & + \\
\hline Islamic Republic of Iran & [22] & 2007 & 21111 & $\begin{array}{l}\text { Different } \\
\text { provinces }\end{array}$ & - & + & + \\
\hline Islamic Republic of Iran & [23] & 2002 & 4315 & Sistan, Guilan & + & - & - \\
\hline Islamic Republic of Iran & [24] & 2004 & 2321 & Tehran & - & + & + \\
\hline Islamic Republic of Iran & [25] & 2006 & 6565 & Tehran & + & + & + \\
\hline Jordan & [26] & 2003 & 5223 & $\begin{array}{l}\text { Different } \\
\text { provinces }\end{array}$ & - & + & + \\
\hline Kuwait & [27] & 2004 & 14659 & $\begin{array}{l}\text { Different } \\
\text { provinces }\end{array}$ & - & + & + \\
\hline Kuwait & [28] & 1998 & 7419 & $\begin{array}{l}\text { Different } \\
\text { provinces }\end{array}$ & + & - & - \\
\hline Kuwait & [29] & 2000 & 8957 & $\begin{array}{l}\text { Different } \\
\text { provinces }\end{array}$ & - & + & - \\
\hline Lebanon & {$[30]$} & 2006 & 12299 & $\begin{array}{l}\text { Different } \\
\text { provinces }\end{array}$ & - & + & + \\
\hline Lebanon & [31] & 2003 & 2104 & $\begin{array}{l}\text { Different } \\
\text { provinces }\end{array}$ & + & + & + \\
\hline Libyan Arab Jamahiriya & {$[32]$} & 2002 & 1614 & $\begin{array}{c}\text { Al Jabel Al } \\
\text { Garby, Tripoli }\end{array}$ & + & - & - \\
\hline Oman & [33] & 2004 & 550 & Muscat & - & + & + \\
\hline Pakistan & [34] & 2001 & 1050 & Karachi & + & + & + \\
\hline Qatar & [35] & 2006 & 3923 & $\begin{array}{l}\text { Different } \\
\text { provinces }\end{array}$ & - & - & + \\
\hline Qatar & [36] & 2004 & 8231 & $\begin{array}{l}\text { Different } \\
\text { provinces }\end{array}$ & + & - & - \\
\hline Saudi Arabia & [37] & 2002 & 12701 & $\begin{array}{l}\text { Different } \\
\text { provinces }\end{array}$ & + & + & + \\
\hline Saudi Arabia & [38] & 1996 & 9061 & $\begin{array}{l}\text { Different } \\
\text { provinces }\end{array}$ & - & + & + \\
\hline United Arab Emirates & [39] & 2006 & 4381 & $\begin{array}{l}\text { Different } \\
\text { provinces }\end{array}$ & + & + & + \\
\hline United Arab Emirates & {$[40]$} & 2005 & 16391 & $\begin{array}{l}\text { Different } \\
\text { provinces }\end{array}$ & + & + & + \\
\hline
\end{tabular}

${ }^{a}$ Studies did not use a uniform scheme for selecting the age groups under study, current categories are used as a basis for comparison, however, numbers indicate the exact the study sample age in each category. 


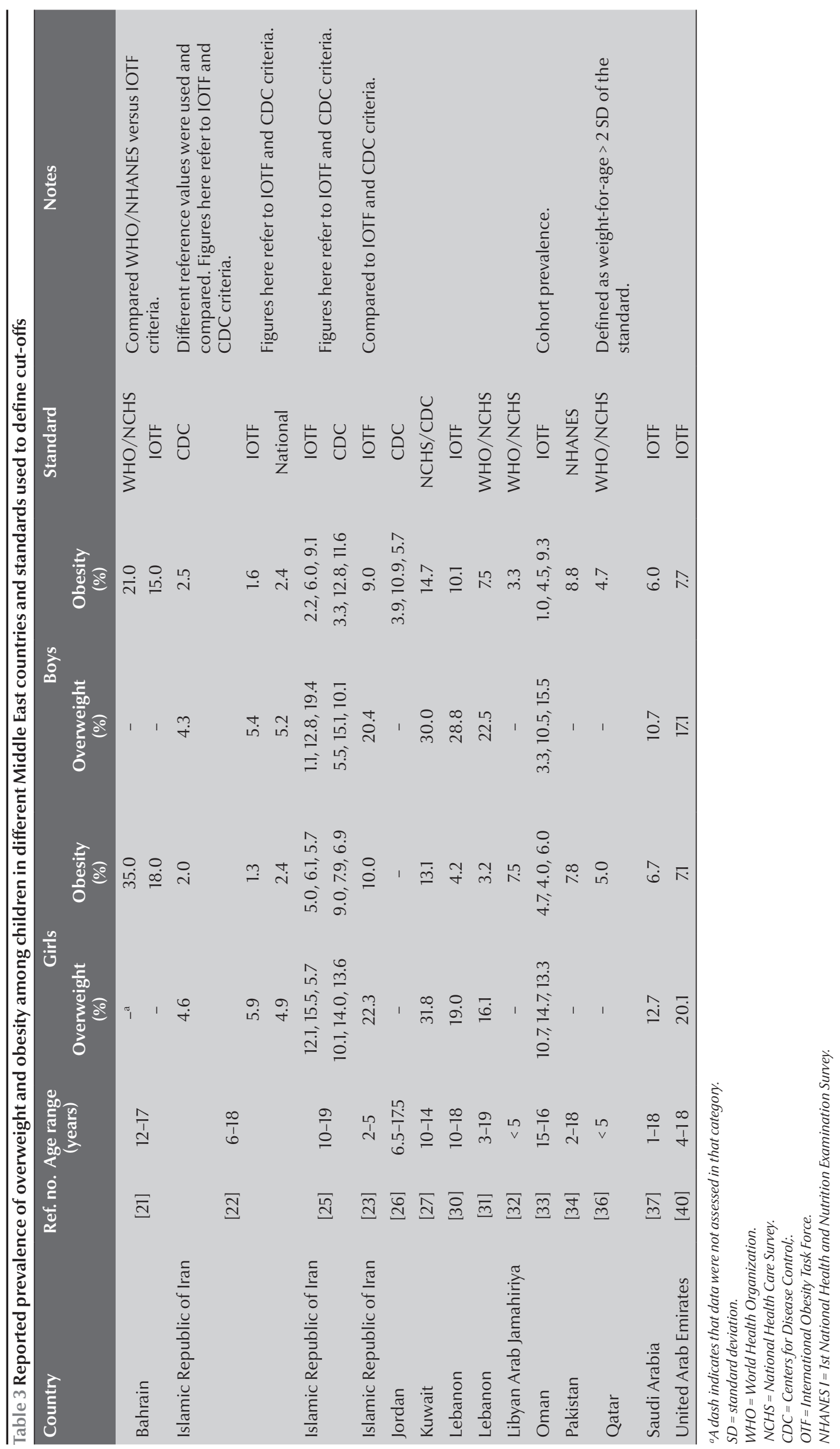


The prevalence of $24 \%$ in the European Union in 2002 was already higher than the predicted peak for 2010 based on original speculations [3]. Some reports place Asia in the third position for overweight among all nations with a prevalence of $2.9 \%$ and an absolute number of 10.6 million overweight children [13]. Reported rates of overweight in Asia vary greatly, from over $30 \%$ in Taipei, Taiwan [2] to $1.7 \%$ in rural areas of China [42]. While there have been several nationally representative nutrition surveys conducted in Asian countries, the focus was on the lower end of the distribution and, thus, rates of overweight were rarely reported.

Internationally, obesity in adolescence has increased greatly over the past 30-40 years, especially since the mid-1990s [3]. The rapid pace of socioeconomic development in the Middle East has led to rapid modernization, accompanied by decreased levels of physical activity and increased calorie consumption. Although very little information is currently available on obesity trends in childhood, the current review seems to confirm a rising prevalence over time. Studies in Saudi Arabia, Islamic Republic of Iran, and Kuwait compared their dataset with similar data from a decade previously, and reported a rising prevalence of obesity among children and adolescents $[24,28,43]$. A study comparing 2 cross-sectional samples of children in Tehran, Islamic Republic of Iran, reported an increasing trend over a 3-year interval [25].

Recent data on adult obesity are alarming and it could be assumed that fat families will raise fat children who will further contribute to the epidemic of obesity-related diseases. This notion is supported by findings from the Islamic Republic of Iran and Untied Arab Emirates $[44,45]$, showing that obese children generally live in obese families. Dietary choices seem to be responsible for familial clustering of obesity $[44,46,47]$.

\section{Prevalence of obesity and overweight by age}

Studies in the Middle East providing a comparison between different age groups indicated a steady increase in the prevalence of overweight/obesity with increasing growth and stage of puberty $[27,33,48]$. The age group at highest risk for overweight/obesity could not be established from this review because there were a limited number of studies in different countries and a lack of uniformity in selecting age groups. A comparison of the rates of overweight among different age groups in 4 Asian and 5 European countries reported that the raw number of cases was highest among 10-year-olds but could not give an accurate estimate of the age group at highest risk for overweight/obesity [2].

\section{Prevalence of obesity and overweight by sex}

The level of fatness among adolescent girls was found to be higher than boys in the NHANES I study in the USA [20]. Our review, however, found a higher prevalence of either overweight or obesity reported among boys than girls from Saudi Arabia, Islamic Republic of Iran, Lebanon, Kuwait and Pakistan $[23,25,27,31,34,49]$. International comparisons also report that the prevalence of obesity is greater among boys than girls in developing countries. Such differences may reflect different cultural habits and attitudes towards nutrition and physical activity [2].

\section{Prevalence of obesity and overweight by socioeconomic status}

Studies from adults find correlations between obesity and socioeconomicstatus (SES), but the results are inconsistent for children [11]. In our review, studies examining the associated social and economic factors revealed that sedentary lifestyles, less physical activity and a tendency towards high-calorie diets was a factor contributing to obesity, as in some countries of the Middle East childhood obesity was most dominant in urban areas and among the higher socioeconomic classes $[26,38,50,51]$. A similar picture was seen in Egypt, where the prevalence of obesity among high SES adolescents was more than double that among low SES groups [52]. A cross-national comparison study came to the conclusion that higher SES children were more likely to be obese in China and Russia, but in the USA low-SES groups were at a higher risk of obesity [11]. A rising trend towards obesity among lower SES groups has been reported from the USA [3], where there is rising concern about the urban and lower-income classes, who seem to be particularly vulnerable because of poor diet and limited opportunities for physical activity. However, in a study in Pakistan, children from middle-income families were more overweight than their counterparts from higher and lower socioeconomic classes [34]. Therefore, the relationship of SES to body fat accumulation is complex and varies across different cultures.

Food consumption patterns and dietary quality are highly incomedependent, but dietary choices, particularly in higher-income groups, are also driven by non-economic forces [16]. Among other factors influencing the obesity epidemic, mothers' level of education and cultural beliefs regarding body image are frequently reported as related factors $[26,38,50,51,53]$. The remarkable variation in the prevalence of obesity across populations suggests that social, economic and environmental factors are important influences on the epidemic, although it may also be true that genetic differences across populations also play a role. 
Standards for defining obesity and overweight

A major problem in interpreting and comparing studies is the use of different standard values for the definition of overweight, as demonstrated in Table 2. WHO is currently raising awareness of the need to establish a consistent and pragmatic definition for childhood obesity to address the issue globally [54]. The definition of obesity among children is not as clear as in adults where BMI (weight/height ${ }^{2}$ ) has been accepted internationally as a standard for assessing obesity [2]. There are several factors such as growth and puberty that influence fat accumulation among adolescents and these make delineating a global standard for assessing overweight and obesity a matter for debate [55].

Traditionally, sex- and age-specific BMIpercentilesbasedonthe NHANES-I surveyin the USA are used to define childhood obesity. Nonetheless, the accuracy of these data as a baseline for estimating fatness among other nations has been disputable $[4,11]$. The evidence supports the notion that lower BMI cut-off points may need to be set for Asian populations, due to their predisposition to deposit fat around the waist $[1,56]$. Investigators point to other problems. For example, the NCHS cut-offs are skewed toward the higher end, reflecting a substantial rate of childhood obesity $[13,19]$.

A WHO expert committee recommended using both the BMI 85th percentile and the triceps skinfold thickness 90th percentile to define adolescent obesity [19]. This has been used infrequently due to the difficulty of measuring triceps skinfold thickness in large population-based studies. Instead, many have chosen to use the BMI 95th percentile to define child and adolescent obesity $[11,20]$. An alternative are the proposed values set by the IOTF, as described earlier. For validating the standards, analysis of the relationship of overweight (according to the defined cut-offs) to levels of adverse risk factors should be conducted, which is a time-consuming and difficult task but has been done for previous standards $[1,2,42,57]$.

Several international efforts are underway to compare different standards with each other. Some indicate that these references produce similar estimates of the overall prevalence of overweight [14]. In a comparison study Wang et al. applied IOTF and WHO criteria in China, Russia and the United States and came to the conclusion that the IOTF was better for international use [58], although Reilly et al. believed that this standard showed a lower sensitivity for defining obesity in English children [59]. Al-Sendi et al. in Bahrain concluded that IOTF cut-offs would be more practical to use [21], but AlAlmaie from Saudi Arabia found no significant difference between IOTF and NHANES criteria [50]. Esmaillzadeh et al. from the Islamic Republic of Iran compared the prevalence of obesity among Tehran children aged 3-5, 6-11 and $12-19$ years old using IOTF reference values and standardized percentile BMI curves of Iranian children [25]. The values for 2001-02 showed that the prevalence of obesity among these age groups was $5.0 \%, 17.6 \%$ and $10.4 \%$ for girls and 2.2\%, $19.5 \%$ and $22.6 \%$ for boys respectively. The corresponding figures for overweight in the same age groups were: $14.1 \%, 12.2 \%$ and $13.7 \%$ for girls and 6.6\%, $15.2 \%$ and $15.4 \%$ for boys. IOTF and CDC cut-offs were also applied and the results covering the largest sample size in each country are presented in Table 3 for comparison. The authors concluded that there was a lower sensitivity for IOTF cut-offs among 6-19-year-old children, while the sensitivity did not differ for the lower age group [25]. Dorosty et al. also showed that obesity prevalence among Iranian children from 2 different provinces using IOTF reference data was significantly higher in 2-3-year-olds than when using the Iranian reference data [23]. Again, there was a comparison between CDC, IOTF and national cut-offs by Kelishadi et al., who found an excellent correlation between IOTF and CDC cut-offs with national cut-off points, yet they reported that IOTF criteria overestimated the prevalence of overweight and underestimated the prevalence of obesity [22]. One explanation for this difference may be that IOTF cut-offs did not include any data from this region. Therefore, current cut-offs used for childhood overweight might not be generalizable to different ethnic groups.

\section{Discussion}

There is a rapid rate of social development and modernization in Middle East countries [22,60], which is causing inequalities in SES within populations [12]. This may to some extent explain the high rates of both overweight and wasting in this region [13]. We should also remember the importance of social norms about diet and activity (among girls and boys) and the culturally determined positive image that being overweight carries in these societies [61]. Although factors such as family history, sedentary lifestyle, urbanization, income and family diet patterns are associated with a high prevalence of overweight and obesity in the Middle East $[26,34,37,38,44,50,51,53]$, it seems that the main underlying causes may be poor knowledge about food choices and lack of physical activity [44]. Investigators in the Islamic Republic of Iran found that nutrient density is not entirely an income-driven issue and, even for the better-off families, satisfaction of needs for nutrients in the diet was only attainable at energy levels of $3000 \mathrm{kcal}$ per day [12]. Hence, to tackle the problem at the country level, it is useful to have as much information as possible about the levels of overweight and obesity (e.g. ethnicity, gender, social class, education, 
habits) in order to target interventions as precisely as possible.

There are several methodological constraints that made the summation and summarization of the different datasets difficult in this review. Different definitions and standard values for assessing body weight status was the principal difficulty, as discussed earlier in this section. Another constraint was the variation among the surveys in the age groups studied and we could not locate a uniform scheme for comparison. In addition, it is likely that the equipment and measurement techniques used were not systematically standardized. Cross-national comparisons should be conducted with caution because a country may have great variation by region, as highlighted in the Islamic Republic of Iran and Saudi Arabia, where different provinces and ethnic groups were studied [22-24,30,31,35,37-40,43]. This may make it difficult to reach a general view of the extent of the problem of overweight and obesity, at least unless nationally representative data are available, but many of the surveys reproduced here do not meet such requirements. Not all of the studies had multiple data points available, thus impeding the estimation of trends in overweight over time. Finally, there may be reports published in journals not indexed in Medline (including local journals), which were not accessed and included in this review.

\section{Conclusions}

This article quantifies the magnitude of childhood overweight and obesity in the Middle East region which can serve as a baseline for assessing future patterns. Although the shift towards a more obese population is perceived from the current literature, few countries in the region enjoy access to nationwide representative data about the extent of this problem. The present estimates can also help identify countries and regions in need of population-wide interventions to prevent childhood overweight, and to encourage cross-national initiatives to establish monitoring and preventing programmes.

\section{References}

1. Freedman DS et al. The relation of overweight to cardiovascular risk factors among children and adolescents: the Bogalusa Heart Study. Pediatrics, 1999, 103:1175-82.

2. Bellizzi MC et al. Prevalence of childhood and adolescent overweight and obesity in Asian and European countries. In: Chen C, Dietz WH, eds. Obesity in childhood and adolescence. (Nestle Nutrition Workshop Series. Pediatric Program. Volume 49.) Philadelphia, Lippincott Williams and Wilkins, 2002:23-35.

3. EU childhood obesity "out of control". International Obesity Task Force [press release] (http://www.iotf.org/popout. asp?linkto=http://www.iotf.org/media/IOTFmay28.pdf, accessed 7 March 2010).

4. Obesity: preventing and managing the global epidemic. Report of a WHO consultation. Geneva, World Health Organization, 1999.

5. Fight childhood obesity to help prevent diabetes, say WHO \& IDF [press release]. Geneva, World Health Organization, 2004 (http://www.who.int/mediacentre/news/releases/2004/ pr81/en/print.html, accessed 5 March 2010).

6. Chinn S, Rona RJ. Prevalence and trends in overweight and obesity in three cross-sectional studies of British children, 1974-94. British Medical Journal, 2001, 322:24-26.

7. Freedman DS et al. The relation of childhood BMI to adult adiposity: the Bogalusa Heart Study. Pediatrics, 2005, 115(1):22-27.

8. The Work of WHO in the Eastern Mediterranean Region: annual report of the Regional Director. Alexandria, World Health Organization Regional Office for the Eastern Mediterranean, 2003.

9. Global strategy for non-communicable disease prevention and control (draft). Geneva, World Health Organization, 1997 (WHO/NCD/GS/97.1).

10. Ogden $\mathrm{CL}$ et al. Prevalence of overweight among preschool children in the United States, 1971 through 1994. Pediatrics, 1997, 99(4):el (doi:10.1542/peds.99.4.e1).

11. Wang Y. Cross-national comparison of childhood obesity: the epidemic and the relationship between obesity and socio- economic status. International Journal of Epidemiology, 2001, 30:1129-1136.

12. Kelishadi R. Childhood overweight, obesity and the metabolic syndrome in developing countries. Epidemiologic Reviews, 2007, 29:62-76.

13. De Onis M, Blossner M. prevalence and trends of overweight among preschool children in developing countries. American Journal of Clinical Nutrition, 2000, 72:1032-1039.

14. Wang $\mathrm{Y}$, Wang JQ. A comparison of international references for the assessment of child and adolescent overweight and obesity in different populations. European Journal of Clinical Nutrition, 2002, 56(10):973-982.

15. Physical status: the use and interpretation of anthropometry. Report of a WHO Expert Committee. Geneva, World Health Organization, 1995 (WHO Technical Report Series No. 854).

16. Bellizzi MC, Dietz WH. Workshop on childhood obesity: summary of the discussion. American Journal of Clinical Nutrition, 1999, 70:173-175S.

17. Defining childhood overweight and obesity. Centers for Disease Control and Prevention [website] (http://www.cdc.gov/obesity/childhood/defining.html, accessed 16 June 2010).

18. Cole TJ et al. Establishing a standard definition for child overweight and obesity worldwide: international survey. British Medical Journal 2000, 320:1240-1243.

19. De Onis M, Habicht JP. Anthropometric reference data for international use: recommendations from a WHO Expert Committee (http://www.unu.edu/Unupress/food/V182e/ch12.htm, accessed 7 March 2010).

20. Must A, Dallal GE, Dietz WH. Reference data for obesity: 85th and 95th percentiles of body mass index $\left(\mathrm{wt} / \mathrm{ht}^{2}\right)$ and triceps skinfold thickness. American Journal of Clinical Nutrition, 1991, 53:839-846.

21. Al-Sendi AM, Shetty P, Musaiger MO. Prevalence of overweight and obesity among Bahraini adolescents: a comparison between three different sets of criteria. European Journal of Clinical Nutrition, 2003, 57(3):471-474. 
22. Kelishadi R et al. Thinness, overweight and obesity in a national sample of Iranian children and adolescents: CASPIAN Study. Child: Care, Health and Development, 2007, 34:44-54.

23. Dorosty AR, Siassi F, Reilly RR. Obesity in Iranian children. Archives of Diseases in Childhood, 2002, 87(5):388-391.

24. Mohammadpour-Ahranjani B et al. Prevalence of overweight and obesity in adolescent Tehrani students, 2000-2001: an epidemic health problem. Public Health Nutrition, 2004, 7(5):645-648.

25. Esmaillzadeh A et al. High prevalence of metabolic syndrome among Iranian adolescents. Obesity, 2006, 14(3):377-382.

26. Majali $\mathrm{H}$ et al. Socio-economic discrepancies in growth status of Jordanian children in military-run schools at the turn of the twentieth century. Saudi Medical Journal, 2003, 24(5):548549 .

27. Al-Isa AN. Body mass index, overweight and obesity among Kuwaiti intermediate school adolescents aged 10-14 years. European Journal of Clinical Nutrition, 2004, 58(9):1273-1277.

28. Al-Isa AN, Moussa MA. Obesity among Kuwaiti pre-schoo children aged 0-5 years: prevalence and comparison with the NCHS/CDC reference population. Nutrition and Health, 1998, 12(4):235-246.

29. Al-Isa AN, Moussa MA. Nutritional status of Kuwaiti elementary school children aged 6-10 years: comparison with the NCHS/ CDC reference population. International Journal of Food Sciences and Nutrition, 2000, 51(4):221-228.

30. Chakar H, Salameh PR. Adolescent obesity in Lebanese private schools. European Journal of Public Health, 2006, 16(6):648-651.

31. Sibai AM et al. Prevalence and correlates of obesity in Lebanon: findings from the first epidemiological study. Obesity Research, 2003, 11(11):1353-1361.

32. Hameida J, Billot L, Deschamps JP. Growth of preschoo children in the Libyan Arab Jamahiriya: regional and sociodemographic differences. Eastern Mediterranean Health Journal, 2002, 8(4-5):458-469.

33. Osman YF et al. Progression of obesity among Seeb school children in Oman. A preliminary study. Saudi Medical Journal, 2004, 25(12):2038-2040.

34. Hakeem R. Socioeconomic differences in height and body mass index of children and adults living in urban areas of Karachi, Pakistan. European Journal of Clinical Nutrition, 2001, 55(4):400-406.

35. Bener A. Prevalence of obesity, overweight and underweight in Qatari adolescents. Food and Nutrition Bulletin, 2006, 27(1):3945.

36. Kamal AA, Bener A, Al-Mulla AK. Growth pattern of Qatari preschool children. Croatian Medical Journal, 2004, 45(4):461-465.

37. El-Hazmi MA, Warsy AS. A comparative study of prevalence of overweight and obesity in children in different provinces of Saudi Arabia. Journal of Tropical Pediatrics, 2002, 48(3):172177.

38. Al-Nuaim AR, Bamgboye EA, Al-Herbish A. The pattern of growth and obesity in Saudi Arabian male school children. International Journal of Obesity and Related Metabolic Disorders, 1996, 20(11):1000-1005.

39. Malik M, Bakir A. Prevalence of overweight and obesity among children in the United Arab Emirates. Obesity Reviews, 2006, 8:15-20.

40. Al-Haddad FH, Bertis L, Ghafar AG. Childhood obesity in United Arab Emirates schoolchildren: a national study. Annals of Human Biology, 2005, 32(1):72-79.

41. Musaiger AO, Gregory WB. Anthropometry of adolescent girls in Bahrain, including body fat distribution. Annals of Human Biology, 2000, 27(5):507-515.
42. Hesketh T, Ding QJ. Standard definition of child overweight and obesity worldwide. British Medical Journal, 2000, 321:11581159.

43. Abalkhail B. Overweight and obesity among Saudi Arabian children and adolescents between 1994 and 2000. Eastern Mediterranean Health Journal, 2002, 8(4-5):470-479.

44. Mirmiran P, Mirbolooki M, Azizi F. Familial clustering of obesity and the role of nutrition: Tehran Lipid and Glucose Study. International Journal of Obesity and Related Metabolic Disorders, 2002, 26(12):1617-1622.

45. Moussa MA et al. Factors associated with obesity in Kuwaiti children. European Journal of Epidemiology, 1999, 15(1):41-49.

46. Al-Mahroos F, Al-Roomi K. Overweight and obesity in the Arabian Peninsula: an overview. Journal of the Royal Society of Health, 1999, 119(4):251-253.

47. Moussa MA et al. Factors associated with obesity in school children. International Journal of Obesity and Related Metabolic Disorders, 1994, 18(7):513-515.

48. Al-Hourani HM, Henry CJ, Lightoweler HJ. Prevalence of overweight among adolescent females in the United Arab Emirates. American Journal of Human Biology, 2003, 15(6):758-764.

49. Al-Almaie SM. Prevalence of obesity and overweight among Saudi adolescents in Eastern Saudi Arabia. Saudi Medical Journal, 2005, 26(4):607-611.

50. Al-Isa AN, Moussa MA. Factors associated with overweight and obesity among Kuwaiti kindergarten children aged 3-5 years. Nutrition and Health, 1999, 13(3):125-139.

51. Kelishadi R et al. Obesity and associated modifiable environmental factors in Iranian adolescents: Isfahan Healthy Heart Program-heart health promotion from childhood. Pediatrics International, 2003, 45(4):435-342.

52. El-Tawila $S$ et al. Transitions to adulthood: a national survey of Egyptian adolescents. Cairo, Population Council, 1999:2530.

53. Al-Rukban MO. Obesity among Saudi male adolescents in Riyadh, Saudi Arabia. Saudi Medical Journal, 2003, 24(1):2733.

54. De Onis M, Blossner M. The World Health Organization global database on child growth and malnutrition: methodology and application. International Journal of Epidemiology, 2003, 32:518-526.

55. Guillaume M. Defining obesity in childhood: current practice. American Journal of Clinical Nutrition, 1999, 70:126-130.

56. The Asia-Pacific perspective: redefining obesity and its treatment. Manila, World Health Organization Regional Office for the Western Pacific/International Association for the Study of Obesity/International Obesity Task Force, 2000.

57. Al-Hazza HM. Physical activity, fitness and fatness among Saudi children and adolescents. Implications for cardiovascular health. Saudi Medical Journal, 2002, 23(2):144-150.

58. Wang Y et al. Standard definition of child overweight and obesity worldwide. British Medical Journal, 200, 321:1158.

59. Reilly JJ, Dorosty AR, Emmett PM, et al. Identification of the obese child: adequacy of the body mass index for clinical practice and epidemiology. International Journal of Obesity and Related Metabolic Disorders, 2000, 24(12):1623-1627.

60. UNICEF at a glance: Bahrain. United Nations Children's Fund [website]. (www.unicef.org/infobycountry/bahrain.html, accessed 7 March 2010).

61. O'Dea JA. Gender, ethnicity, culture and social class influences on childhood obesity among Australian schoolchildren: implications for treatment, prevention and community education. Health and Social Care in the Community, 2008, 16(3):282-290. 